\title{
Disability: a justice-based account
}

\author{
Jessica Begon ${ }^{1}$
}

\begin{abstract}
Most people have a clear sense of what they mean by disability, and have little trouble identifying conditions they consider disabling. Yet providing a clear and consistent definition of disability is far from straightforward. Standardly, disability is understood as the restriction in our abilities to perform tasks, as a result of an impairment of normal physical or cognitive human functioning (in combination with our social, political, and environmental context, and our resource share). However, which inabilities matter? We are all restricted by our bodies, and are all incapable of performing some tasks, but most of these inabilities are not considered disabilities. If, then, we are to avoid the category of disability becoming overly broad - and thus politically and practically useless-we need some way of picking out the specific inabilities that are disabling. I argue that our answer should be informed by an account of the opportunities individuals are entitled to be able to perform as a matter of justice. Thus, to be disabled is to have these opportunities restricted, and not to deviate from the species norm or lack any ability that might improve our well-being.
\end{abstract}

Keywords Disability · Impairment · Distributive justice · Well-being · Species functioning

Jessica Begon

jessica.e.begon@durham.ac.uk

1 School of Government and International Affairs, Durham University, The Al-Qasimi Building, Elvet Hill Rd, Durham DH1 3TU, UK 


\section{The problem of defining disability}

My goal is to defend a new account of disability: one that is indexed to an account of distributive justice, or what individuals are entitled to. Yet it may seem that determining how disability should be defined needs no further investigation. Most people have a clear sense of which conditions they consider disabling. Further, there is broad philosophical consensus on some central features of an account of disability. First, there is a widely accepted distinction between impairment as physical or cognitive features that cause deviation from a biological or statistical norm of species functioning, and disability as a restriction in our ability to perform tasks. ${ }^{1}$ There is considerable agreement, too, that disability is caused in part by impairment, and in part by an individual's social and political context, and the resources they have access to. ${ }^{2}$

I do not intend to challenge the consensus on either point. Rather, I ask: if disability is the restriction in our ability to perform tasks, then which inabilities matter? In other words, which of the limitations that result from individuals' impairments, in combination with their context and resources, should be considered disabling? We are all restricted by our bodies, and are all incapable of performing some tasks, but most of these inabilities are not considered disabilities. An account of disability is an essential prerequisite to formulating public policies that safeguard the just treatment of disabled individuals, and an account cannot form the basis of such policy if it simply concludes that 'everyone is disabled'. If, then, we are to avoid the category of disability becoming overly broad-and thus politically and practically useless - we need some way of picking out which inabilities are relevant to defining disability. Only then can we identify and respond to the injustice, discrimination, and mistreatment to which so many disabled individuals are subject.

I begin, in Sect. 2, by considering and rejecting alternative accounts of which inabilities are disabling: those entailed by 'normal' species functioning (Buchanan et al. 2000; Daniels 1985), those that undermine well-being (Kahane and Savulescu 2009; Savulescu and Kahane 2009), and those considered relevant by disability activists (Barnes 2016a). I demonstrate that the latter approach leaves disability underspecified, whilst on the former two approaches disability will be ubiquitous. As such, all of these alternatives prove an inadequate basis for public policy, political campaigning, or activist movements. I argue, instead, that the relevant opportunity losses involve restrictions of individuals' entitlements (Sect. 3). Thus, I define disability as the restriction in the ability to perform those tasks human beings

\footnotetext{
1 For example: Terzi (2004), Nussbaum (2006), Shakespeare (2006), Smith (2001), Buchanan et al. (2000), Oliver (1996). Though some recent work questions this distinction (Barnes 2018, 2016a).

2 In other words, we should reject both a strict medical model of disability (according to which disability is straightforwardly caused by individual impairment), and a strict social model (which denies this causal relationship, insisting instead that disability is solely the result of unjust social structures). Whilst social structures can certainly be disabling, it is also clear that disability could not be eliminated by social changes alone (Barclay 2010: 161; Shakespeare 2006: 46; Terzi 2004). Hence, we should adopt a hybrid account, which acknowledges the influence of social factors, without ignoring the impact of impairment (for example, Wolff 2009a; Kahane and Savulescu 2009; Shakespeare 2006; Terzi 2008; Daniels et al. 2009).
} 
are entitled to be able to perform as a matter of justice, as the result of the interaction between an individual's impairment, their social and political context, and the resources they have available to them. This provides a framework account of disability. To determine whether an impairment is actually disabling will require an account of our distributive entitlements, but this is not a prerequisite to accepting the general claim that individuals are disabled when their access to these entitlements is restricted (as a result of their impairment and context). (As subsequent discussions will illustrate, the case of disability does give us some reason to favour particular accounts of distributive justice over others, but I will not attempt to mount a definitive defence of one particular approach here.)

In Sect. 4 I consider some possible objections to the definition I have sketched. First, it may seem that if being disabled means lacking what we are entitled to, then in cases where this cannot be rectified, this cannot be unjust. This implies individuals with serious impairments would not be considered disabled on my account. Second, in part to avoid the former objection, I adopt a broadly-specified and multiply-realisable conception of entitlements: for example, as opportunities for mobility, communication, or forming relationships. This leaves me vulnerable to the further worry that individuals will not be considered disabled, or entitled to assistance, even when unable to perform important functionings (walking, hearing, easily reading social cues) if they have more general capabilities in these domains. I respond to these objections in Sects. 5 and 6.

I finish, in Sect. 7, by considering the revisionary and counterintuitive implications of my account. It will, for example, imply that individuals with significant and visible impairments may not be disabled by them, that individuals with apparently minor or invisible impairments may be disabled, and that individuals' status as disabled may change across time and context. However, I argue that far from giving us a reason to reject my approach, this is one its key benefits. The intuitions with which this approach may clash ought to be challenged: our understanding of disability should no longer focus on bodily difference or deviation from what we take to be the norm, and should instead reflect a concern with the opportunities that all individuals ought to have access to, and which are closed to so many.

\section{What disability is not}

\subsection{Disability and impairment}

In this section I outline and critique alternative accounts of disability. However, I do not challenge the distinction between disability and impairment, or the consensus that the cause of disability involves both individual impairment and wider context. This terminology is worth clarifying. Impairment can be understood as "departure from human normality" (Terzi 2008: 43) or atypical forms of physical or cognitive functioning, and might include blindness, deafness, and mobility impairments, as well as non-standard cognitive functionings experienced by individuals with autistic spectrum conditions (ASCs), Down's syndrome, or Alzheimer's. Disabilities are the 
"activity limitations, and participation restrictions" that may result (WHO 2017). There are various views on which such limitations are disabling. For example, those who subscribe to a species norm approach deem the relevant functioning restrictions to be those "that individuals in someone's reference group (e.g. adults) are ordinarily able to do" (Buchanan et al. 2000: 286). The goal of the paper is to defend a different approach.

Distinguishing disability and impairment draws attention to the contingency of the connection between bodily and cognitive difference and having a disability, which also depends on context, resources, and personal features. Indeed, highlighting this contingency was a major motivation behind the development of the social model by the disability rights movement. ${ }^{3}$ Further, as we will see, this distinction both allows us to campaign against disability, as restriction, without suggesting that we should seek to normalise human bodies and minds by eliminating impairments, and enables us to describe the shared experience of atypical functioning of those who have an impairment, whether they are disabled by it or not.

Nonetheless, objections may be raised against this terminology. First, whilst common among disability scholars and activists, outside this community this language might strike some as clumsy and counterintuitive. We are very used to calling people with impairments - of vision, mobility, cognitive function-disabled, without paying much attention to the restrictions in activity or participation they may or may not face. It may seem awkward to insist that an individual in a wheelchair - often the literal poster-child of disability - is merely impaired, and that this might not translate into a disability. Yet this discomfort is often grounded in the unexamined assumption that differences in physical and cognitive functionings must manifest themselves in restrictions of ability, and the associated belief that the impaired body or mind is, itself, the problem. These intuitions, however strong, ought to be questioned, as the disability rights movement has long argued.

A second, more serious worry concerns the potential normative implications of labelling individuals 'impaired'. This is not intended to be an evaluative concept. It simply provides a way of distinguishing disability, which (partially) results from impairment, from other forms of disadvantage, such as that associated with some racial or gender identities, or sexual orientation. ${ }^{4}$ Further, (almost) everyone in some way deviates from the norm; hence, has an impairment. Nonetheless, this term has connotations of deficiency, defect, and imperfection. It may, therefore, seem more

\footnotetext{
3 The social model not only drew a conceptual distinction between impairment and disability, but, in some iterations, disputed the causal connection between them (see fn.2).

4 This is in addition to the other noted benefits: highlighting both the contingency of the connection between impairment and disadvantage, and the shared experience of atypical functioning. A further reason to accept this distinction is that I am not convinced by the arguments of its primary opponentBarnes (2016a: 23-28, 2018) — for its rejection. Briefly, these are: first, that our judgements about who is impaired rely on our intuitions about disability, and that there is no distinct explanatorily and extensionally adequate account of impairment; and, second, that this will lead to an overly disembodied view of disability focussing merely on social exclusion and ignoring the "messy reality" of having a disabled body (Barnes 2018: 1158). I believe these claims can best be refuted with a neutral account of impairment, though I cannot rehearse these arguments here (see Begon (unpublished).) For further critiques of Barnes's view of impairment, see Howard and Aas (2018) and Francis (2018).
} 
apt to refer to 'difference', 'diversity', or 'heterogeneity'. I do not do so only to avoid the proliferation of competing terminology. However, to emphasise, impairment is synonymous with difference rather than deficiency.

Yet this neutral account of impairment may seem to leave my approach vulnerable to a third objection: that it will render the category of disability overinclusive. As noted, part of the reason to accept the standard distinction between disability and impairment is that this helps to distinguish disability from other forms of socially-mediated disadvantage. However, if impairment implies mere atypicality (rather than deficiency) then it may still seem to include almost everyone: even individuals with better than normal functioning may count as impaired, in obvious tension with its usual meaning. The most straightforward response here is to note that accepting my general account of disability does not hang on accepting this view of impairment. It is possible to agree that individuals are disabled when they lack the opportunities they are entitled to, though to focus on cases in which this results from functioning in a 'deficient' or 'unhealthy' way.

More substantively, I believe both that there are positive reasons to adopt a neutral account of impairment, and that this will not render disability problematically over-inclusive, though I lack the space to fully defend either claim here. ${ }^{5}$ To briefly tackle the over-inclusiveness worry: first, it is true that better functioning individuals will count as impaired (assuming functionings can meaningfully be described as simply 'better', as opposed to better suited to a particular context). However, describing Michael Phelps (to take Barnes's (2016a: 14-15) oft-cited example) as impaired is hardly implausible if this just means he functions atypically. The important question is whether he is disabled-whether he lacks opportunities he is entitled to-and it is clear that he is not. A broad account of impairment does not necessitate a broad account of disability, then. Second, racial identity and sexual orientation will not count as impairments insofar as racial

\footnotetext{
5 See Begon (unpublished). In brief support of the neutral approach: first, it avoids the implication that the appropriate response to impairment must be to cure or eliminate it, which seems to follow if impairment is taken to imply deficiency or ill-health. Second, it avoids the difficult task of determining which ways of functioning are non-contextually worse: whilst certain forms of physical and cognitive functioning do not fit well with some environmental contexts it is far from straightforward to identify a principle that determines which deviations from the norm are simply negative. Finally, the neutral approach provides a means of responding to a worry that might be raised about under-inclusiveness: if impairment is deficiency then those whose functioning cannot plausibly be described as deficient, such as some autistic persons, will not be considered disabled. One means of avoiding such exclusion is to allow that individuals may be disabled if they are merely perceived as, or treated as if, they are impaired [indeed, the ADA has taken this approach (see Francis 2018 for discussion), and for a defence of this position see Aas (2016) and Howard and Aas (2018)]. This move is unnecessary if impairment merely implies difference: these individuals straightforwardly count as impaired insofar as their functioning is atypical, and are disabled if they lack opportunities they are entitled to. No claim about deficiency is necessary. Thus, we need not attempt the thorny challenge of formulating an account of deficiency. Nor need we distinguish those in the disabled community who are 'really' impaired (i.e. defective) and those who are wrongly perceived as such. For further arguments against this approach see Begon (unpublished). However, it is worth emphasising that accepting the central claim of this paper does not demand acceptance of these arguments: perhaps individuals are disabled when they lack the opportunities they are entitled to as a result of being perceived to function in a deficient (or, indeed, merely atypical) way.
} 
phenotypes and preferences cannot plausibly be described as functionings. ${ }^{6}$ Sexbased differences may seem to present a harder case since there do seem to be differences in the functional capacities of average male and female-bodied persons, most obviously (though not only) relating to differences in their reproductive capacities. We do not need to accept the existence of a strict binary, or a metaphysically deep reason to appeal to reference classes based on sex categories, to allow that our assessment of typical functionings can be indexed to the capacities of biological females and males. Thus, a male is not impaired by their inability to bear young. ${ }^{7}$ A neutral account of impairment, then, need not lead to the inclusion of other forms of disadvantage in the category of disability.

\subsection{Species norm accounts}

I therefore accept the distinction between disability and impairment, where the latter concept will make some reference to normal species functioning, but nonetheless reject accounts where disability itself comprises the loss of species-normal abilities. The most obvious worry is that these accounts will be over-inclusive since individuals depart from the species norm in many trivial (or even beneficial) ways. Raising an eyebrow might be a species-normal ability, but those who lack it surely are not disabled. Allen Buchanan et al. (2000: 285) attempt to avoid this problem by distinguishing "impairment of normal species functioning" from disability as the resulting inability to perform a significant range of tasks. To illustrate, they consider someone who cannot hear sound at a particular range of frequencies, yet in whose environment nothing "she is likely to be required to do or would benefit from doing" requires hearing sound in this range (Buchanan et al. 2000: 287). This individual thus has an impairment, but this does not translate into a disability.

\footnotetext{
${ }^{6}$ I assume that preferences and appearance do not constitute ways of functioning though they may be functional, but I lack the space to defend this view. Thanks to an anonymous reviewer for raising this point.

7 It might seem that trans persons are a difficult case to accommodate here. Whilst I cannot attempt a full account of this complex and controversial topic, it is not immediately obvious that this must be so. Roughly I would suggest, first, that either conforming to, or subverting, socially-constructed gendered behaviours should not be considered a form of physical or cognitive functioning, but a preference about how to live our lives. Thus, individuals whose gender presentation is non-binary or does not conform to their assigned sex should not be understood as having an atypical functioning capacity. Second, individuals who change their sex identity or change their body to corresponded to their true sex might be impaired if they are unable to perform functionings that are typical for this sex. For example, trans women who are unable to bear young or menstruate could be said to function atypically, and could potentially be disabled too, depending on the consequences of such restrictions, just as natal women who cannot so function might be. This does not imply that there is anything pathological about mere possession of a trans identity, thus following the DSM-5 (2013) in accepting that "gender nonconformity is not itself a mental disorder". \{I leave aside, here, the question of whether there may nonetheless be reasons for trans persons to choose to adopt a disabled status if this is the only way to ensure their rights are protected [as Wahlert and Gill (2017) argue]\}. This would not hold true if we do not believe individuals can choose or change their sex, in which case these trans women would be normal functioning male-bodied persons with female gender identity and presentation - and thus not impaired. I take no view on which approach is correct, but merely sketch how they may be accommodated. For further discussion of these issues see, for example, Bettcher (2014a, b), Dembroff (forthcoming), Jenkins (2016).
} 
However, this distinction between inabilities to perform species-normal functionings and species-normal tasks is difficult to draw-at least, without some additional account of which of these tasks are 'significant'. Indeed, in describing their example, Buchanan et al. (2000: 287) make reference to what we might "be required" to do or "would benefit" from doing. By (implicitly) drawing on these ideas they can avoid the inclusion of trivial inabilities. However, this also suggests that their means of identifying relevant restrictions is not purely based on a species norm, and so is no longer a species norm approach.

Furthermore, this approach's focus on 'tasks' may mean it is under-inclusive. Consider, for example, individuals who suffer from chronic pain, anxiety, or depression, but who are nonetheless high-functioning and able to perform all species-normal tasks (or those they are required to do, or that benefit them). These cases are analogous to the individual who cannot hear particular sound frequencies: they may not function as normal, but this does not translate into a restriction in their abilities. Yet it is implausible to suggest that individuals who struggle with pain, anxiety, and depression are not disabled until this manifests in an inability to perform tasks. Buchanan et al. could respond by adopting a more expansive understanding of tasks, and thus of disability. They might point out that performing tasks whilst suffering is not species-normal: we should not focus just on what people can achieve but on whether their method of achievement is normal. This response would, indeed, allow them to include individuals with chronic pain, depression, and so on, but would seem to come at the cost of also including their hearing-impaired person, and other trivial cases. After all, the species-normal way of performing the task of hearing includes, inter alia, not being in pain and hearing sound frequencies within a certain range. This fully inclusive approach is both implausible and contrary to their stated view. The route out would involve an appeal to which of the atypical ways of achieving a task are relevant or significant and this, as noted, takes us beyond the appeal to mere species norms. (As Sect. 6 will consider, this route is open to me since I am explicitly committed to a principle that identifies which of the various ways of performing atypical functionings are disabling.)

Accepting an account of impairment grounded in species norms does not raise the problems that plague this approach to disability. First, impairment should be an expansive category. Thus, we need not resist the inclusion of the individual with the mild hearing impairment, and those with anxiety, depression, and chronic pain - and even those who cannot raise an eyebrow, or Michael Phelps. This does not imply that disability must be similarly all-encompassing since, unlike Buchanan et al., I explicitly offer a criterion to identify which of the associated restrictions are disabling. Second, if impairment is normatively neutral-synonymous with difference, not defect-it is not vulnerable to a final objection often raised against species norm accounts of disability. This is the worry that focussing on an idealised conception of normal species functioning entails a corresponding disrespect of, and insult to, those who fail to meet this ideal. For example:

the whole ideology of normal functioning is seen as primarily constructed...to control and exclude disabled people from active and full participation in social 
and institutional arrangements which have no interest in accommodating them.

(Terzi 2009: 90)

An account of impairment that is indexed to species norms merely acknowledges that many (or all) of us are not 'normal' in various ways and, whilst not problematic in itself, this can, in some circumstances, prevent us from having the opportunities we are entitled to. The same can be said of gender and racial identities and sexual orientation without implying any such identity is deficient.

\subsection{Welfarist accounts}

The second account of disability I will consider is the welfarist approach. This is most clearly and explicitly defined and defended by Kahane and Savulescu (2009: 53 ), according to whom disability is a:

stable physical or psychological property of subject $S$ that tends to reduce S's level of well-being in circumstances $\mathrm{C}$, when contrasted with a realistic alternative, excluding the effect that this condition has on well-being that is due to prejudice against $S$.

Thus, the relevant inabilities, on this view, are those that reduce welfare.

Perhaps the most obvious problem with this account concerns the difficulties in developing an account of welfare. Whilst Kahane and Savulescu aim to remain neutral between alternative accounts, there are problems with any that might be incorporated. This reflects the more general difficulties with formulating a clear and satisfactory account of welfare, which cannot be rehearsed here. ${ }^{8}$ However, in brief: first, a subjective account of welfare, relying on the individuals' self-assessment, will inevitably raise reliability concerns. The various ways in which self-reported levels of happiness, contentment, or preference-satisfaction, can be misleading have been well-documented. ${ }^{9}$ Yet moving toward a more objective understanding of welfare brings its own problems. For example, the difficulty of finding a nonarbitrary way of compiling a list of basic goods, or the worry that this list will entail the paternalist imposition of a perfectionist conception of the good, or that it will be elitist and exclusionary. Further, we may be sceptical about the implication that something can be considered good for someone independently of their attitudes towards it, and indeed, despite their own insistence to the contrary.

A further problem in the social justice context is the epistemic difficulty of assessing welfare in many cases. For example, Kahane and Savulescu (2009) discuss the 'Ashley treatment', named after a child with severe cognitive impairments who was given treatment to restrict her further growth and prevent puberty. They argue that though this treatment moved Ashley further from the species norm, it lessened her disability since it improved her welfare. This stands in stark contrast to, for example, Eva Feder Kittay's discussion of the case, in part

\footnotetext{
8 Some of the many contributions to this debate include: Scanlon (1975, 1998), Griffin (1986), Crisp (2006), Sumner (1996), Parfit (1984).

9 For example, Kahneman et al. (1982), Elster (1987), Khader ( 2011).
} 
because Kittay employs a different understanding of Ashley's welfare. She contends that "[w]e take pleasure and pride in our bodies as they grow and mature because...we do. Full stop. It needs no further justification. It is constitutive of a thriving life" (Kittay 2011: 621). Yet evidently Kahane and Savluescu do not recognise this value. These epistemic difficulties are especially intractable in cases such as Ashley's where it can be hard to ascertain the view of the individual concerned, and far from clear that those who have not experienced this condition can understand what would be required for her to thrive.

Thus, Kahane and Savulescu's definition does not determine who is disabled, but simply moves the debate to a new context: finding a satisfactory account of welfare. This is an important gap in their approach. However, the fact they have not filled it does not mean it cannot be satisfactorily filled (though given how long this debate has raged, scepticism regarding its speedy resolution seems justified). Further, a welfarist might respond that disability should not be easy to define, and that my own approach will face similar worries - there is, of course, no consensus on what justice demands. However, these epistemic worries are, perhaps, deeper for welfarist approaches - at least for those that include an element of subjectivity in their account of welfare-since they necessarily require a direct reliance on first person testimony. Moreover, whilst we may not have reached agreement on a complete theory of justice, it might be easier to agree on basic entitlements and so basic injustices than it is to identify core instances of welfare deficit. Further, we may need to agree on certain essentials of a theory of justice, unlike welfare, if we are to determine how the benefits and burdens of social cooperation are to be distributed (Rawls 1999: 5). For example, it is, perhaps, easier to agree that individuals are entitled to equal political participation, opportunities for mobility, and the ability to form relationships than it is to show that all these capabilities will make all individuals better-off, given the existence of the idiosyncratic preferences of the politically apathetic, sedentary, and misanthropic. Thus, disagreements about what makes life go well may be harder to settle even in apparently core cases, as examples like Ashley illustrate. Yet welfarists could doubtless disagree. As such, noting the lack of a widely-accepted account of welfare raises a worry that demands a response, rather than providing a decisive refutation of the welfarist view.

The deeper problem for this view is that, whatever account of welfare is used, disability will be ubiquitous, and this will prove problematic from the perspective of justice and public policy. As Kahane and Savulescu (2009: 30) openly acknowledge, disability will be a degree rather than a threshold concept. Thus, "everyone has disabilities of one kind or another". ${ }^{10}$ I agree that there can be a degree of

\footnotetext{
${ }^{10}$ Arguably, Terzi's (2008, 2009) approach could also be included as welfarist. Terzi adopts a capability approach to disability, and so understands impairments as disabling insofar as they cause a loss of, or restriction in, capabilities. However, she understands the capability approach as an account of subjective well-being, and so considers the loss of capabilities to entail the loss of components of well-being. Thus, individuals are disabled by capability loss because this renders them worse off. For example, she suggests that whether a wheelchair user has a capability depends on her "most valuable ends" and her "attitude" (Terzi 2009: 99): if these are such that she cannot fulfil her goals as the result of being in a wheelchair "her well-being appears to be restricted... and hence the full set of capabilities available to this person is diminished" (Terzi 2009: 100). If we interpret Terzi as implying individuals are disabled whenever their
} 
arbitrariness in determining the boundaries of disability. I agree, too, that we have reasons to expand this category (as Sect. 7 discusses). Nonetheless, we should be cautious of expanding it so far that it becomes meaningless, as it will be if it is a category in which everyone is included.

If every stable physical or psychological property that lowers our welfare counts as disabling, then this definition does not seem to pick out the right cases-or, not only the right cases. At least, not in the context of social justice, where our concern is identifying disadvantage and determining how the state should appropriately respond. It is certainly worth emphasising that disability is a continuum, and that we are all restricted by the limitations of our bodies and minds. Nonetheless, when fighting against ableism and injustice, simply concluding that 'we are all disabled' is unhelpful. Similarly, we may wish to reject binaries of sexual orientation and gender identity, and deny that racial categorisation is possible, yet nonetheless find it useful to refer to 'women', and 'gay people', and 'black people' as a means of identifying, and fighting against, injustices against these groups. 'Disability', I contend, has value and meaning as a way of identifying, and responding to, disadvantage. The term has little function if entirely ubiquitous. ${ }^{11}$

\subsection{Barnes's social constructionist approach}

Barnes, like many others, rejects the social model's exclusive focus on external causes of disability, and emphasises that our understanding of disability should be grounded in an assessment of individuals' physical features-or, "what their body is (really) like" (Barnes 2016a: 38). ${ }^{12}$ However, she also emphasises that particular qualities are considered significant not because of their objective features, but because of how we think about them. Barnes further argues that those best placed to determine which features should be considered disabling are disability activists. Thus, "disability just is whatever the disability rights movement is promoting justice for" (Barnes 2016a: 43). Inclusion in the category of disability therefore depends on "rule-based solidarity among people with certain kinds of bodies" (Barnes 2016a: 46).

However, there may be problems with relying on such rules. First, we should not unquestioningly accept the content of these rules. Whilst disabled individuals' testimony should undoubtedly play an important role in developing an account of disability, it does not follow that the rules adopted by the disability rights movement will be free of bias. Individuals who already 'count' as disabled may have vested interests in excluding others from entering this group, and perhaps diluting the strength of their claims with the accretion of many others. This need not be a

\footnotetext{
Footnote 10 continued

well-being is restricted and capabilities diminished as a result of an impairment, then disability would also be ubiquitous on her account.

11 Further, though we do not want to replicate a common-sense understanding of disability, it should not be entirely divorced from our intuitions. Indeed, Kahane and Savluescu (2009: 19) themselves object to the species norm approach on this basis.

12 Barnes discusses only physical, and not cognitive, disabilities.
} 
conscious process of exclusion. Individuals may simply tend to see their own impairments as the paradigm, and be less inclined to include those they are less familiar with. Thus, we should not assume that disabled individuals' epistemically privileged position regarding their own experience extends to understanding the diverse experiences of all disabled people. ${ }^{13}$ Nor can we assume that a group fighting against injustice will never unjustly exclude others. Consider, for example, the exclusion of asexual individuals by some in the LGBTQ + community, or the exclusion of trans women by some feminists. The point is not that such exclusion is unjust, but that the question is not resolved by observing that existing members of the community determined these boundaries. ${ }^{14}$

A related worry is that, given the heterogeneity that exists between and within such groups, disagreement about the content and application of the rules of inclusion seems likely, and difficult to resolve. Barnes (2016a: 49) acknowledges the diversity of disability rights movements, and allows that it may be "simply vague or indeterminate which social group is referred to...[as] 'the disability rights movement"". Her response is to insist that "this entire domain...is riddled with indeterminacy" (Barnes 2016a: 49), and that it would be "deeply implausible" if it turned out that "any aspect of our complex, multifaceted social reality had fully determinate boundaries" (Barnes 2016a: 50). It is true that any definition will likely include borderline cases. Indeed, an account that provides a firm and unequivocal distinction seems to have missed something important about the category of disability. Yet even if the boundaries are somewhat indeterminate, we still need some sense of where they lie, and I am sceptical that the implicit rules used by disability rights movements will be sufficient for this task. ${ }^{15}$

Further, I believe there are deeper flaws in Barnes's approach, which can be seen by considering two criteria Barnes (2016a: 10-13) sets out for a successful account of disability: first, that it should not prejudge normative issues and, second, that it should deliver the correct verdict about paradigm cases. These criteria will not be met by my account, but I contend that an account of disability need not-and, indeed, should not attempt to--fulfil these criteria. Considering the latter first, it is not clear why it would be a virtue of an account to be 'correct' about paradigm cases. Whilst we may worry about an approach that bears no relation to our understanding of disability - for example, an account that includes homosexualitywe should also be aware that our sense of the 'paradigm' is often informed by intuitions that are based on prejudice about, and misunderstanding of, disabled lives. ${ }^{16}$ As noted, these worries may not be solved by allowing those who are already considered part of this 'paradigm' to be the arbiters of who else will be included.

\footnotetext{
13 For a discussion of the impact of restricted information on the reliability of individuals' choices and preferences see Begon (2018a).

14 Similar worries are raised by Campbell and Stramondo (2016), Wasserman (2018), and Howard and Aas (2018: 1127).

15 Also see: Wasserman (2018: 254), Howard and Aas (2018: 1115), Francis (2018).

16 As Sect. 7 considers and Barnes (2016a: 119-142, 2009) herself has pointed out.
} 
Next, Barnes (2016a: 11) insists that "[i]t should not be built into the very definition of disability that disability is something that's bad or suboptimal". However, it is only important that disability be value-neutral if we follow Barnes in rejecting the distinction between impairment and disability. ${ }^{17}$ If we accept this distinction, we can allow that disability is necessarily disadvantageous and still maintain a normatively neutral account of impairment, capturing the heterogeneity of human bodies and capacities, which may be disadvantageous in some contexts but need not be so. This does not undermine the possibility of being proud of our diverse bodies and minds. However, conflating these terms makes it near impossible to achieve the twin goals of recognising that diversity need not be negative, and that it can be correlated with disadvantage, which must be identified to be rectified.

Barnes meets her own criteria, and so argues that disability is a 'mere difference'. Yet this does not mean it has no effect on individuals' lives. On the contrary, it "may be good for you, it may be bad for you, it may be utterly indifferent for you" (Barnes 2016a: 98). Indeed, Barnes allows that being disabled may sometimes lower overall well-being, that some aspects of some disabilities are bad-differences (Barnes 2016a: 75), and even that some specific disabilities are bad simpliciter [something that makes "your life go worse in virtue of it specifically" (Barnes 2016a: 87; 102)]. By including diverse conditions within this wider category, it becomes true that disability is not necessarily a bad-difference, but this category still encompasses conditions (whether few or many) that are bad-differences. ${ }^{18}$

Clearly, then, Barnes does not believe that "the positive effects [of disability] have to balance the negative ones", and accepts that "in the world we inhabit, disability tends to significantly reduce one's good options" - contra the claims of some of her critics (Kahane and Savulescu 2016: 777, 776). ${ }^{19}$ Nonetheless, espousing a 'value-neutral model' or 'mere-difference view' of disability can be importantly misleading, especially if this is used to ground general claims about the kinds of policies that should be pursued with regards to disability. Certainly we should acknowledge that it is "simply untrue that, as a general rule, disabilities are bad for those who have them" (Campbell and Stramondo 2017: 176). Thus, claims rooted in the general assumption that someone's life will be worse simply because they have 'a disability' are unjustified. ${ }^{20}$ However, we should also avoid grounding claims about policy on the assumption that all disabilities should be treated as neutral simply because this category incorporates conditions with good, bad, and neutral effects. For example, we may accept that disability is a mere-difference in Barnes's sense, but still believe, contra Barnes (2014, 2016a), that it is sometimes wrong simpliciter to cause some disabilities. ${ }^{21}$ Amalgamating all disability into a

\footnotetext{
17 See Begon (unpublished) and Sect. 2.1 for a defence of this distinction.

18 In other words, Barnes's conception of neutrality is very weak (see Wasserman 2018: 254-256; Hawkins 2018: 463-466; Dougherty 2014).

19 For Barnes's response, see Barnes (2016b).

${ }^{20}$ More precisely, since unlike Barnes I distinguish impairment and disability: because they have an impairment widely assumed to be disabling.

21 See Begon (2018b); Wasserman (2018: 255).
} 
general 'value-neutral model', then, can obscure the disadvantage that can be associated with impairment. ${ }^{22}$

How problematic this is may depend on the context in which our account of disability is employed. My focus here is relatively narrow: aiming to develop an account that can guide theory and policy that aims to identify and mitigate the disadvantage associated with physical and cognitive difference. Such policies should be nuanced and individualised, as I will argue. They must acknowledge that some impairments, for some people, in some contexts, are not neutral-or merely "a minority body" (Barnes 2016a: 1) —and should not be treated as such. Thus, in this context, at least, it seems unwise to remain committed to a unified category of disability so broadly construed.

Like the welfarist account, then, Barnes's approach shifts the focus of the debate rather than settling it: determining how to respond to disability will require identifying which aspects of which disabilities are bad differences. Neither approach settles the question of when disability is a disadvantage of the kind the state should mitigate. Thus, neither approach can form the basis of public policy or political activism. Whilst we must have a value-neutral account of physical and cognitive difference (which I call impairment), we also need a concept that can play a role in political debates about when difference is disadvantageous, what constitutes injustice towards disabled individuals, and the policies that should be pursued to respond to this.

\section{Which inabilities matter?}

Not all restrictions in individuals' capacity for activity and participation are disabilities: we are not disabled if we cannot sing, cannot stand on one leg, or cannot raise an eyebrow. This is so even if these abilities are species normal, and even if restrictions in them decrease our welfare. I argue that the relevant restrictions are in abilities that individuals are entitled to be able to perform. I will begin by considering a specific application of this approach: the case of deafness. The impairment here is the inability to hear, whilst the disability is the reduction in relevant opportunities that may arise when most people communicate via speech, such as difficulties in political participation, access to appropriate education, and forming meaningful relationships. Deaf individuals are not disabled on the basis that they are unable to hear music, or the voices of their loved ones. However, this need not be because opportunities for aesthetic experience or forming relationships are

\footnotetext{
22 As such, Campbell and Stramondo's (2017: 163-165) suggestion that disabilities are intrinsically neutral, but not instrumentally, comparatively, or overridingly neutral, seems a more plausible and nuanced view. Nonetheless, there may be reasons to worry that their account could also be employed in a way that obscures disadvantages associated with impairments insofar as they tend to consider disabilities "in isolation from their effects" (Campbell and Stramondo's 2017: 163), where this is usually taken to mean those that are most obviously detrimental to well-being. It is not clear that uncontroversially harmful elements of impairments such as pain, fatigue, or disturbed or depressed emotional states can be meaningfully isolated from these conditions. However, I lack the space to defend this claim here (see Begon (unpublished)).
} 
not considered central entitlements. On the contrary, they may well be central-we simply do not need to hear music or voices to have them. Being entitled to opportunities in a domain need not require having every opportunity. Thus, if deaf individuals have access to other aesthetic experiences, their inability to hear music is not a concern of justice. Indeed, if deaf individuals have all the opportunities they are entitled to, they are not disabled.

My claim, then, is that individuals are disadvantaged when their access to their entitlements is restricted, and disabled when this results from an impairment (in combination with context, resources, and personal characteristics). ${ }^{23}$ Thus, individuals with the same impairments may not be identically disabled, and individuals' status as disabled may change over time even if their impairment does not alter. Rightly, then, we cannot know whether an individual is disabled merely from information about their impairment. The account is intended to be a framework into which various theories of distributive justice can be incorporated. Accepting the general claim that individuals are disabled when their impairments restrict their access to forms of activity and participation they are entitled to does not require accepting a particular conception of entitlements.

However, there is (at least) one approach to distributive justice that cannot be incorporated. My account distinguishes what individuals are entitled to from what merely decreases their welfare. As such, it cannot accommodate those welfarist approaches that consider anything that lowers individuals' welfare-whether state oppression or stubbing our toe-to constitute a relevant disadvantage. Subjective accounts, which do not distinguish the different reasons for a decrease in hedonic state or the different sorts of preferences individuals may care to have satisfied, would collapse into the welfarist accounts discussed in Sect. 2.3 and so face the same worries about over-inclusiveness and the ubiquity of disability raised there. ${ }^{24}$ My approach relies on the general anti-welfarist intuition that "[s]ome deprivations of capabilities [or resources] express greater disrespect than others, in ways any reasonable person can recognize" (Anderson 1999: 332). This distinction is employed widely in the distributive justice literature, by theorists who disagree on

\footnotetext{
23 This approach may seem similar to Haslangerian models of disability (see Haslanger 2000; Barnes 2016a: 28-38; Howard and Aas 2018), and certainly shares the goals of her ameliorative project. On one plausible iteration of a Haslangerian account, to be disabled is to be in a bodily or psychological state assumed to be an impairment in the prevailing ideology, where this marks one out for pity, stigma and exclusion, and where the fact one is in this state plays a role in one's systematic disadvantage (Howard and Aas 2018: 1113, 1128-1129). Unlike the account I defend here, this approach is focused not on the specific "valuable activities" individuals are excluded from Howard and Aas (2018: 1113), but with the cause of this exclusion: that it results from possession of a feature that, within the dominant ideology, marks one for this exclusion. As such, this view will be more and less inclusive than my own. Individuals may be disabled though they face very little actual disadvantage [for example, Oscar Pistorius (Howard and Aas 2018: 1129)]. Further, individuals may not be deemed disabled though they face a restriction in opportunities they are entitled to due to atypical bodily or cognitive functioning, if this atypicality is not assumed to be an impairment in the prevailing ideology (for example, the case of obesity discussed in Sect. 7, which though clearly stigmatised is not generally pathologised as an impairment in Howard and Aas's sense).

24 It is worth noting that it is both implausible that individuals are disabled by anything that lowers their subjective welfare, and implausible that such individuals lack what they are entitled to as a matter of justice, though I cannot defend this stronger claim here.
} 
much else, and has strong intuitive pull. ${ }^{25}$ It is the suggestion that individuals should be entitled to vote in elections, to be mobile, and to access educational opportunities, but are not entitled to access every ride in an amusement park, or a sports car, or an expensive musical instrument-and that this is so even if they would prefer these latter opportunities, and they would have a greater positive impact on their welfare. In other words, this is the claim that only some domains of life are the concern of justice, and that the scope of these domains is not determined by individuals' preferences.

Beyond this restriction, then, adopting a specific theory of justice is not a prerequisite to accepting my account of disability. However, it is difficult to defend this account in the abstract, and cumbersome to run through every possible way to cash out individual entitlements. Thus, I will talk in specific terms, employing an approach with three key features. First, I will assume individuals are entitled to capabilities, understood as control over certain domains of their life, rather than merely access to resources (Begon 2017). Second, our conception of entitlements should be relatively thick: not merely entailing the fulfilment of basic needs, but including access to opportunities such as forming social relationships, engaging in leisure activities, and enjoying aesthetic experiences. Finally, I assume that individuals are entitled to broadly specified opportunities, and not particular or identical functionings: for example, opportunities for aesthetic experiences, mobility, or communication, and not hearing music, walking, or talking. ${ }^{26}$ These features have not been selected at random. I believe there are good reasons to opt for an account of distributive justice with these features, and that reflection on disability can help demonstrate why this is so, as much of the subsequent discussion will illustrate. However, I certainly cannot definitively refute all alternative understandings of entitlements here, so will leave it to their adherents to demonstrate how they can navigate the issues disability raises.

\section{Feasibility, levelling-down, and thinning-out}

I will now outline some possible objections to the account I have sketched, and in responding to them in subsequent sections will elucidate my account. First, it may be objected that if being disabled means lacking opportunities we are entitled to, then impairments that result in the loss of significant opportunities will not be considered disabling if we cannot prevent this loss, since we cannot be entitled to an opportunity it is impossible to provide. Thus, if, due to lack of medical or technological knowledge, or merely lack of resources, we cannot prevent

\footnotetext{
25 For example, Anderson (1999), Dworkin (2000: 61), Carter (2014: 84-85). I will not defend this distinction here (see Begon 2016).

26 Approaches that accept some version of the second criterion but not the third-i.e. an expansive, but narrowly specified set of entitlements-are common (arguably including: Dworkin 2000; Nussbaum 2000; Cohen 2011; Rawls 1999; Anderson 1999). I have defended the third criteria elsewhere (Begon 2017). Also see Asch and Wasserman (2005) for an argument that individuals need not have access to every opportunity.
} 
individuals being rendered immobile, unable to communicate, or to form relationships, then they cannot be entitled to these opportunities, and cannot be considered disabled by their absence. If this were so, serious impairments-perhaps the most serious impairments-would not be considered disabling on my account. Clearly, this would be very counterintuitive.

Further, this understanding of our entitlements presents a dilemma. On the one hand, this may lead us to conclude that individuals with serious impairments should simply have different entitlements. That is, if some individuals can only be provided with a restricted set of opportunities, then their entitlements are correspondingly diminished. On the other hand, we may wish to resist this tiered, non-universal approach to entitlements, and insist instead that all humans are entitled to the same opportunities (though not, of course, to the same outcomes). Yet this seems to imply that the content of everyone's entitlements should reflect the unavoidable constraints on some individuals' functioning. In other words, that we can be entitled only to what can be provided to all. If we grasp this latter horn, the content of our entitlements might start to look rather thin. This is implausible in itself and will generate an implausible account of disability if my approach is employed. For example, if we cannot currently enable everyone to control their mobility then no one can be entitled to this opportunity, and individuals whose control over their mobility is impaired are not disabled by their inability.

However, this is an artificial dichotomy. If we reject an implausibly strict egalitarian view, according to which everyone must be enabled to perform an identical set of functionings, and instead consider individuals to be entitled to generalised opportunities-for example, mobility, not walking (i.e. the third criterion outlined above) - then it may seem that everyone can have the same entitlements. Thus, we can avoid a tiered approach without levelling-down our entitlements to include only those capabilities to function that can be universally provided. That is, we should recognise that capabilities are multiply-realisable, and treat different functionings as interchangeable and equally valuable. This will mean that many individuals with impairments can have the opportunities they are entitled to even if there are some functionings they cannot perform. Thus, even if we were to limit our entitlements to those that could be provided universally, this might eliminate less than it initially seems.

Nonetheless, this response will not prove fully satisfactory. First, even if the opportunities individuals are entitled to are generalised and multiply-realisable there will still be some cases in which they cannot be provided. Staying with the example of mobility: though individuals with many mobility impairments can be enabled to control their mobility, this may not be possible for individuals with locked-in syndrome. Further, the very focus on multiply-realisable capabilities may generate a further objection about the 'thinning-out' of individuals' entitlements. It might seem that if those who use a wheelchair have sufficient opportunity to be mobile, then they have all they are entitled to. Thus, if, for example, it were possible to restore functioning to a paraplegic person's legs, even at very little cost, they would neither be entitled to demand this from the state nor considered disabled if the treatment were not provided. This is an instance of the more general worry that sufficientarian approaches, by only ensuring individuals reach some threshold of achievement, may 
fail to eliminate radical, and potentially unjust, inequalities above this threshold. If capabilities can be experienced in various ways, then individuals are neither considered disabled by their inability to perform specific functionings (walking, talking, hearing, seeing) nor entitled to be enabled to perform them, just as long as they have more general capabilities (for mobility, communication, leisure, aesthetic experiences) at some appropriate level. I will now respond to these objections.

\section{Identifying distributive entitlements}

I turn, first, to the objection that individuals with serious impairments will not be considered disabled if the opportunity loss associated with their condition cannot be avoided; and, further, that we will therefore face the dilemma of either decreasing entitlements for this subset of individuals or levelling-down entitlements generally. This is based on the assumption that the demands of distributive justice must be realisable: that if an individual is entitled to something, it must be feasible to provide it to them. However, we need not accept this assumption. ${ }^{27}$ It is quite plausible to suggest that we are currently unable to rectify some instances of injustice. Thus, some individuals may not be able to access opportunities that justice requires they have. If a just state of affairs is not currently realisable then they cannot have a claim that anyone now provides these opportunities, though they do have a claim that we work towards a situation in which their provision is feasible. If, for example, we believe all humans are entitled to control over their mobility, then this cannot mean the state has an obligation to provide this to someone with lockedin syndrome if this is impossible. However, they do have an obligation to enable them to have such control if it were, and to work towards releasing this state of affairs. Further, the individual with locked-in syndrome is disabled because they cannot be provided with an opportunity that they should have access to: that they should be enabled to perform if this were possible.

A situation in which some individuals lack opportunities that everyone should be entitled to may be unjust, then, even if no one is guilty of causing this injustice and no one has a direct duty to rectify it. Some may find the suggestion that entitlements should be conditional in this sense implausible: how can we be entitled to something no one has a duty to provide? It is worth noting, first, that the alternative approach has similarly unappealing implications: if we want a universal list of entitlements and can only include items on this list when they can currently be provided to every individual, then we may not even have a general right to nourishment, say, if it is currently logistically impossible to ensure everyone has this opportunity. We may, therefore, accept that some entitlements should lack a feasibility constraint, but believe these conditional or proto-entitlements should be distinguished from entitlements proper, where the former are what all individuals are (conditionally) owed as a matter of justice and the latter are those claims that we can press against a

\footnotetext{
27 I cannot attempt to conclusively refute the feasibility constraint on justice here, but for an excellent argument for its rejection, see Gheaus (2013).
} 
specific duty-bearer. The former constitute part of the content of a theory of distributive justice: the list of capabilities (or primary goods or human rights) to which all individuals have a (conditional) entitlement, even if they temporarily cannot be provided with every item on this list. Indeed, this captures what seems so objectionable about situations in which individuals do not have the opportunities (or resources, or rights) we think they ought to: individuals may not be wronged when they cannot be mobile, or nourished, and so on, but they should have these opportunities if it were possible and we should work to make this so.

The important point is not the choice of terminology, but the general claim that the set of entitlements specified by a theory of distributive justice are, in a sense, owed to all, even when this obligation cannot feasibly be met. The sense in which they are owed is that these opportunities (resources, rights) should be provided if they can be, and that the state (or other relevant body) should not artificially limit the boundaries of the possible. This means that not all disability will be the result of unjust behaviour - though, of course, some will be. Sometimes the state may fail to fund research to develop technologies that increase impaired individuals' functioning capacity, or design material infrastructure in avoidably exclusionary ways. Yet sometimes the restrictions to individuals' entitlements may be ineliminable and unavoidable: perhaps due to natural obstacles, perhaps due to competing claims on a limited pool of resources, or to conflicts between different forms of accommodation (certain policies may render some impairments non-disabling (indeed, may be the only way to do so) whilst at the same time exacerbating others). Thus, the content of our (conditional) universal distributive entitlements should not be determined by what it is feasible to provide universally.

Understanding entitlements in this way means we need not grasp either horn of the above dilemma: we can have a universal set of entitlements that is not levelleddown to include only those opportunities that can be achieved by all. However, this does not imply that the content of our entitlements can or should take no account of feasibility whatsoever. We could, for example, take the view that humans should be entitled to the opportunities necessary for a decent life, where this will be informed by our reasonable expectations of what such a life entails. On this view, controlling our mobility might be central to such a life; the ability to fly would not be. Further, the content of our reasonable expectations for a decent life can be predicted to change over time, as technology improves. The point, here, is not to identify the specific content of our distributive entitlements, nor even to outline the method by which they would be determined. Rather, it is to note that this might depend on what it is possible for humans to do, and on what we think humans ought to be able to do, without implying that all these entitlements must currently be achievable for every human. In other words, entitlements can be indexed to what is feasible for most, without requiring that they can be provided to all (though we should strive to achieve this).

Two further objections may be raised against this response. First, if our entitlements depend to some extent on our reasonable expectations about a decent (or dignified, or flourishing) human life, and our expectations are informed by what humans, as a species, can generally do, then this might seem to collapse into a species norm approach. That is, our entitlements are simply identical to species- 
normal functionings. Yet this is not the case. Even without specifying the content of our entitlements we can see that they will be both narrower and broader than species-normal functionings. They will be narrower, first, because on any plausible view trivial human capabilities will not be central entitlements (the ability to roll our tongue, sing, or stand on one leg). Individuals who thus deviate from the species norm do not lack opportunities they are entitled to. Our entitlements are narrower, too, if understood as general opportunities, rather than the performance of specific functionings. An individual can have what they are entitled to (the capability for mobility, say), even if there is a species-normal functioning they cannot perform (walking using their own legs). Additionally, our entitlements will be broader, since we may be entitled to more opportunities than those that are 'natural' or normal for our species. ${ }^{28}$ As medical, social, and technological progress expands the scope of human capacities, our reasonable expectations of a decent life and the opportunities we should be entitled to will surely reflect this.

A second objection concerns the potential ambiguity regarding when it is 'feasible' to provide an opportunity, given that this may require radical expense of time or resources. There are two forms of this worry. First, if we could all be enabled to fly, say - if the government were to divert all research funding to this project-then should this opportunity be an entitlement, which we are disabled in the absence of? Clearly the answer is no. When this is a mere abstract possibility, such a functioning is unlikely to feature in our reasonable conception of a decent life, or what we can reasonably expect from the state. However, I would concede that if a way of enabling humans to fly were discovered and made available to the majority, then we might expand our conception of our entitlements to include this. ${ }^{29}$ In this imagined scenario this is no more a reduction ad absurdum of my approach than acknowledging that individuals' capacity for mobility should take account of modern transportation and that, as such, someone who could only get around at the speed and distance walking and running would usually allow may not have what they are entitled to in this domain. To emphasise: insisting that we can be entitled to opportunities it is infeasible to provide universally does not mean our entitlements must be entirely unmoored from what is feasible for most.

Second, and perhaps more troubling, are cases in which an opportunity is available to most individuals, but can only be provided to a minority at great expense. For example, if an individual with locked-in syndrome can control their mobility only with an extremely expensive piece of equipment, are they entitled to it? No doubt there will be many difficult cases, but our approach to such questions must involve weighing up the capabilities provided to the minority against those lost by the majority. Thus, if the cost of providing this equipment meant others suffered premature death or significant impairment then the individual surely cannot be entitled to their mobility in the face of these costs. In this case, we can continue to

\footnotetext{
28 The species norm approach will be restricted to 'natural' human abilities if we follow Daniels (1985: 28) and derive it from the "design of the organism", rather than "merely a statistical notion".

29 Thanks to Paul Billingham for pushing me to clarify this point.
} 
say that it is impossible for the individual to be mobile and they are unavoidably disabled, since their entitlements cannot be provided at a reasonable cost. ${ }^{30}$

\section{Beyond minimal functionings}

I now turn to the worry that understanding entitlements as general, multiplyrealisable opportunities will mean that individuals will not be considered disabled even when they lack important opportunities. First, I consider Anita Silvers's objection to what she takes to be capability theorists' approach to educational provision for individuals with impairments. This, she claims, would only provide "educational opportunity adequate for a dignified life, which...may not even...rise to the level of average educational attainment" (Silvers 2009: 181). Silvers discusses a child with a hearing impairment, who struggles to catch all the information imparted in class due to the difficulty of lip-reading in this context. Nonetheless, she is denied a translator since her educational attainment is already above average (Silvers 2009: 177-182). Silvers objects that it is unfair that children with impairments are unable to fulfil their potential simply because their educational environment is not designed to support them. Further, it might seem that, on my view, these children would (implausibly) not be considered disabled by this restriction in their access to education, because 'they already have what they're entitled to'.

However, contra Silvers, a decent education surely requires more than the opportunity for some minimal educative outcome, such as passing grades. ${ }^{31}$ More plausibly, this requires something like 'the opportunity to develop our potential to a similar degree as our peers'. This must be at least part of the goal of education, and we would fail to show individuals equal concern and respect if we provided this to some and not others. ${ }^{32}$ This does not mean that there will not be difficult cases, where the needs and requirements of different children pull in different directions, and limitations of resources mean that an ideal learning environment cannot be provided for everyone. However, as discussed, the fact that something cannot

\footnotetext{
30 This does not imply scarcity is wholly irrelevant to our entitlements. Again, my claim is only that the possibility of universal provision is not a prerequisite to something being an entitlement. Feasibility, including considerations of scarcity, may play a role in determining where the boundaries of our entitlements lie: for example, as discussed, via informing our reasonable expectations about the shape of a decent life. Returning to the above example, if individual jet-pack technology were created but was prohibitively expensive and/or relied on a resource too scarce for it to be made available to all, then this is not likely to feature amongst our reasonable expectations and thus our entitlements. In contrast, if this could be provided near-universally, became the dominant mode of transport and a prerequisite for participation in various aspects of social and political life, then this may be amongst our (conditional) entitlements.

31 The same is true if we focus on other criteria to identify entitlements, such as leading a dignified or flourishing life. Indeed, if a criterion did not have this implication, this would surely count as a reason against its adoption.

32 See Terzi (2008) for a capability approach to education for children with impairments.
} 
currently be universally provided does not mean that we cannot reasonably include this amongst our entitlements.

Yet it may be objected that education is a special case. Whilst the very goal of education involves enabling individuals to develop their talents and abilities, having opportunities for mobility, communication, or leisure surely does not require being able to fulfil our potential in these domains. It seems much more plausible to suggest that we are here entitled to something like acceptable options and the capacity to meaningfully choose between them. As such, individuals who achieve mobility with a wheelchair rather than by walking, or communicate using Sign rather than speech, or look at art because they are unable to listen to music, are not considered disabled by this restriction in their ability to function; nor would they be entitled to an operation to restore the use of their legs, or cochlear implants to restore their hearing, even if this would not be costly.

In these cases, I would bite the bullet-though with some important caveats. I would accept, then, that if we lived in circumstances in which individuals with impairments had all the opportunities they are entitled to then they should neither be considered disabled nor necessarily entitled to state assistance. For example, if an individual with a mobility impairment could control their mobility without being dependent on others, then they may not be entitled to be enabled to walk. ${ }^{33}$ Similarly, a deaf individual who had access to leisure activities and aesthetic experiences (and every other capability they are entitled to) would not be entitled to cochlear implants to allow them to hear music. Nor would these individuals be considered disabled.

The caveats, though, are to point out, first, that often individuals with impairments do not have what they are entitled to. In many cases the restrictions in their capabilities are avoidable, and could be eliminated by changing social infrastructure and norms. However, this is not always so. In some instances, this is because we lack the technology or resources to prevent some impairments from restricting individuals' opportunities. In others, this is because individuals' needs conflict, and there is no way to structure the external environment that would eliminate all restrictions. For example, "[p]eople with mobility issues who do not use wheelchairs may find that steps are safer and easier for them than ramps...[w]heelchair users may have problems with tactile paving which gives locational cues to visually impaired people", and so on (Shakespeare 2006: 46). These cases can prove as intractable as those in which we simply lack the ability to institute the relevant change. As such, the appropriate way to mitigate the disadvantage associated with an impairment may not be to change the environment, and this might be so even when the disadvantage is a result of that environment. Thus, to conclude that if an impairment were not disabling (did not result in relevant restrictions) an individual would not be entitled to state assistance does not imply that now, or in the near future, treatments that mitigate impairments would not be provided.

\footnotetext{
33 Exactly how much of their environment would have to be inaccessible to conclude that an individual lacks control over their mobility is ambiguous, and I will not attempt to settle this question here.
} 
The second caveat is to note that suggesting that such treatments may not be a matter of entitlement does not imply that they are banned or restricted. Any liberal approach to distributive justice will aim to ensure both fairness in distribution, and individuals' freedom to form and pursue their own conception of the good. Thus, if an individual desires to walk, or hear, or see, they will not be prevented from pursuing these goals. Indeed, in a situation in which individuals had access to all the central capabilities (or primary goods, or equality of Dworkinian resources) there would be sufficient resource equality that individuals would have the ability to achieve these goals (especially on the above assumption that these treatments are inexpensive). Indeed, my account does not even rule out state provision or subsidy of these options on the grounds of public choice, if the decision is procedurally just and does not divert resources from the satisfaction of actual entitlements. ${ }^{34}$

One final sense in which our entitlements might seem too minimal on my approach relates to an objection earlier raised against the species norm approach. This is, that by focussing on what individuals are able to do, I take insufficient account of how much more difficult this may be when we have an impairment. Someone who uses a wheelchair, for example, may have the capability for mobility, but this will often be restricted by both the built and natural environment. Thus, they may find travelling much more physically demanding than, for example, walking a similar distance. Or, an individual in chronic pain may be able to perform all the functionings that a person without this condition can, yet they must struggle against the pain that accompanies every functioning they perform. I certainly want to resist the implication that the difficulty of performing tasks would not be considered a relevant dimension of disadvantage, and that individuals who experience such difficulty would not be considered disabled, nor entitled to assistance to mitigate it.

Whether this is indeed an implication of my approach depends on the sensitivity of our conception of distributive entitlements not just to what we can do, but also to the pain and effort that must be expended to do it. I would contend that such concerns should feature in our understanding of individuals' entitlements. ${ }^{35}$ Although I cannot provide an independent defence of this here, it is important to note that insisting that a theory of distributive justice is sensitive to these considerations is not merely a post hoc modification to ensure that my definition of disability remains plausible. On the contrary, the above examples give us reason to think that individuals should be entitled not just to the mere capacity to perform some functionings, but to be able to do so without associated pain, and without having to expend massively more energy than others to achieve the same outcome. Thus, the point is not that an account of our entitlements that ignored the pain and effort required to achieve them would generate an implausible account of disability if my framework is employed, but that this would be an independently implausible account of our entitlements.

\footnotetext{
34 Thanks to Carl Fox for helping me clarify this point.

35 For approaches that do so, see Wolff and de-Shalit (2007), Wolff (2009a, b), Cohen (2011), Anderson (1999). It may be a problem with Nussbaum's $(2000,2006)$ and Sen's $(1999,2009)$ approaches that they do not clearly incorporate such concerns.
} 


\section{What counts, who's disabled?}

I will finish by considering whether my account will prove to be too revisionary. Certainly, the impairments that would be considered disabling do not neatly cohere with our intuitions in a number of cases. As emphasised from the outset, my account will imply that individuals with visible impairments may not be disabled by them, that individuals with seemingly minor or invisible impairments may be disabled, and that individuals' status as disabled may change across time and context. However, far from giving us reason to reject this approach, this is one of its key benefits. As Sect. 2.4 discussed, there is little point in devising a definition that captures all paradigm case when we have good reason to think the paradigm is informed by prejudice and misinformation.

First, many paradigm impairments, such as deafness, blindness, paraplegia, achondroplasia (a common form of dwarfism), ASCs, and Down's syndrome need not be disabling on my account. If individuals have the opportunities they are entitled to-perhaps as a result of adequate infrastructure, access to resources, and lack of bias - they will not be considered disabled merely on the basis of their impairment. Disability does not consist in bodily or cognitive difference, but in specific opportunity losses that might result. This does not imply that we cannot campaign for the better treatment of individuals with impairments, or for their access to their entitlements. However, we should not assume that having an impairment, especially a visible impairment, must be disadvantageous. We should, instead, focus on the specifics of each case and determine whether an impairment is actually associated with restrictions in individuals' activity and participation. The reality often will not accord with our unexamined intuitions. ${ }^{36}$

My approach will also produce deviations from the paradigm in the other direction: many non-paradigm cases, such as depression and anxiety, and even obesity or shyness, might be disabling. Further, individuals who have body integrity identity disorder (the strong desire to amputate a healthy limb) may be disabled by being prevented from undergoing this amputation, insofar as living with a limb they disassociate from disrupts their access to capabilities: for example, making social interaction difficult. ${ }^{37}$ I will consider perhaps the most controversial of these examples: obesity. I am aware that both disabled and obese individuals will likely object to this implication, given the unjustified stigma attached to both labels. It is worth emphasising, then, that though I consider an obese body an impairment (after all, it is a deviation from the species norm), I am not suggesting that it worse, or

\footnotetext{
36 As noted in Sect. 2.1, part of the motive behind the introduction of the social model, and the rhetoric of claiming that "disablement is nothing to do with the body" (Oliver 1996: 35), was to resist the medicalisation of disability and to highlight the contingency of the connection between impairment and disadvantage.

37 For discussion of these cases, see Bayne and Levy (2005), Müller (2009).
} 
necessarily disadvantageous, to have such a body. However, this is a dimension of difference, like many others, that may be associated with disadvantage. ${ }^{38}$

My focus is not the possible (and sometimes controversial) correlation between obesity and health conditions such as high blood pressure, diabetes, heart attack, or stroke. Even leaving these aside merely having an obese body can be disabling. Our built environment is made for human bodies of a particular size and weight. As Gay (2017: 184) says, "[t]here are very few spaces where bodies like mine fit". One simple and important example is chairs: aeroplane seats, restaurant booths, lecture theatres, cinema seats. If these cannot accommodate individuals with larger bodies, this can be hugely restrictive to those who possess them, limiting opportunities to be mobile, to access education, or to engage in many leisure activities. In addition, an obese body may be restrictive independently of the design of material infrastructure, rendering "impossible" activities like standing for long periods or walking a mile uphill (Gay 2017: 16). Finally, the bias, stigma, and abuse obese individuals are often subject to, the commentaries on their bodies by friends, family, medical professionals, and strangers, and the assumptions made about their capacities may further limit their capabilities. Options may be closed to them because others assume they are incapable of exercising them (for example, not being offered certain jobs), or they may lack internal capabilities (for example, not feeling qualified to apply for these jobs in the first place). ${ }^{39}$ In all these ways, obesity-like other forms of physical and cognitive difference-can be disabling.

The final counterintuitive implication is that what counts as a disability on my view will be contextualised, and may change over time. This can happen in at least three ways. First, as society becomes better able to accommodate impairments, and enable different forms of functioning, then these impairments will cease to be disabling. This is not because these impairments are 'cured', but because their link with disadvantage is severed. For example, if the oft-discussed examples of deafness and mobility impairments no longer lead to capability loss, then individuals with these impairments may not be disabled, though they still cannot hear or walk unaided. Whilst this may seem counterintuitive to some, it accords with the experience of many disabled individuals, who do not regret, or demand compensation for, the different ways they function. Consider, for example, Harriet McBryde Johnson's (2003) account of the pleasures of wheelchair use, and the misperceptions of those who do not use one:

I used to try to explain the fact that I enjoy my life, that it's a great sensual pleasure to zoom by power chair on these delicious muggy streets, that I have no more reason to kill myself than most people. But it gets tedious...they don't want to know. They think they know everything there is to know just by

\footnotetext{
38 There are, of course, some differences correlated with disadvantage that we would not want to describe as disabilities, such as our gender or racial identity, or sexual orientation. As Sect. 2.1 considered, this need not be an implication of my view.

39 In Nussbaum's (2000: 84) terminology, internal capabilities are "developed states of the person herself that are...sufficient conditions for the exercise of requisite functions". Whether restrictions in internal capabilities constitute a loss of entitlements depend on the conception of entitlements we employ. Again, such examples may give us reason to incorporate them.
} 
looking at me. That's how stereotypes work. They don't know that they're confused.

Second, as our capacity to provide opportunities changes, individuals may be entitled to more if the content of our entitlements depends on our reasonable expectations. For example, we now expect leisure time, aesthetic experiences, and a longer life than previously. Impairments that restrict access to these new entitlements will then count as disabling, though individuals' actual abilities have not changed. One example here might be (some forms of) dyslexia. In a context in which many are illiterate, this is unlikely to be disabling. In a context in which a grasp of the written word is a prerequisite for many other opportunities, it would be. Thus, dyslexic individuals may become disabled over time, or by moving. Consider, for example, a dyslexic girl who emigrates from rural Gambia, where illiteracy is rife and educational infrastructure underdeveloped, to the UK, where she has better access to education, though her dyslexia is not fully accommodated. Whilst she is now less disadvantaged (she now has access to education), she may also become disabled insofar as it is now her impairment that restricts her access to education (where previously it may have been poverty or sexism). Again, this seems to be the right way to understand such cases.

Lastly, individuals who have impairments that involve periodic and perhaps unpredictable flare-ups, such as fatigue and pain conditions, may have a changeable disability status. Some will be disabled only during a flare-up, some may be disabled during periods when flare-ups are common, and for some the mere possibility of a flare-up may render them consistently disabled. For example, an individual with epilepsy may never be able to drive a car, or an individual with ME may struggle to retain employment if their impairment necessitates frequent absences.

\section{Conclusion}

It is a consequence of my approach that individuals are not categorised as disabled in the way we might expect, and that who is included in this category may change. Yet surely it is right to set aside our preconceptions about how bad some impairment must be and focus instead on the actual restrictions individuals face, and on which of these should be the focus of our concern. What matters - what is disabling - is that individuals are rendered (often contingently) unable to be mobile, unable to communicate or form social relationships, or unable to access education or meaningful work as a result of their impairments. Not that they are unable to walk, unable to listen to music, or unable to read emotional cues easily. Whatever account of distributive justice is used, then, my approach to disability will be revisionary and contrary to many common-sense intuitions about who is disabled. However, these implications constitute a feature, not a bug. Our present intuitions concerning what constitutes disability often reflect prejudice and bias, and should be altered. Further, our account of disability should change over time, and reflect what individuals are able to do, and what we think they ought to be able to do. The problem of disability is the problem of losing significant opportunities-and not the 'problem' of 
deviation from the species norm, or the loss of our irrelevant opportunities-and our understanding of disability should be reoriented to reflect this.

Acknowledgements For helpful comments and discussion of earlier drafts, I would like to thank Alice Baderin, Ian Carroll, Cécile Fabre, Carl Fox, Katherine Jenkins, and audiences at the Royal Institute of Philosophy Seminar at the University of Nottingham, the Nuffield Political Theory Workshop, the Priority in Practice Conference at the University of Oxford, the Association of Social and Political Philosophy Conference at the University of Sheffield, and the Political Philosophy Seminar at the University of Newcastle, as well as an anonymous referee.

Open Access This article is licensed under a Creative Commons Attribution 4.0 International License, which permits use, sharing, adaptation, distribution and reproduction in any medium or format, as long as you give appropriate credit to the original author(s) and the source, provide a link to the Creative Commons licence, and indicate if changes were made. The images or other third party material in this article are included in the article's Creative Commons licence, unless indicated otherwise in a credit line to the material. If material is not included in the article's Creative Commons licence and your intended use is not permitted by statutory regulation or exceeds the permitted use, you will need to obtain permission directly from the copyright holder. To view a copy of this licence, visit http:// creativecommons.org/licenses/by/4.0/.

\section{References}

Aas, S. (2016). Disabled-therefore, unhealthy? Ethical Theory and Moral Practice, 9, 1259-1274.

American Psychiatric Association: Diagnostic and Statistical Manual of Mental Disorders, Fifth Edition (DSM-5). (2013). Arlington, VA.: American Psychiatric Association.

Anderson, E. (1999). What is the point of equality? Ethics, 109, 287-337.

Asch, A., \& Wasserman, D. (2005). Where is the sin in synecdoche? In D. Wasserman, J. Bickenbach, \& R. Wachbroit (Eds.), Quality of life and human difference: Genetic testing, health care (pp. 172-216). New York: Cambridge University Press.

Barclay, L. (2010). Disability, respect and justice. Journal of Applied Philosophy, 27, 154-171.

Barnes, E. (2009). Disability and adaptive preference. Philosophical Perspectives, 23, 1-22.

Barnes, E. (2014). Valuing disability, causing disability. Ethics, 125, 88-113.

Barnes, E. (2016a). The minority body: A theory of disability. Oxford: Oxford University Press.

Barnes, E. (2016b). Reply to Kahane and Savulescu. Research Philosophica, 93, 295-309.

Barnes, E. (2018). Against impairment: Replies to Aas, Howard, and Francis. Philosophical Studies, 175, 1151-1162.

Bayne, T., \& Levy, N. (2005). Amputees by choice: Body integrity identity disorder and the ethics of amputation. Journal of Applied Philosophy, 22, 75-86.

Begon, J. (2016). Athletic policy, passive well-being: defending freedom in the capability approach. Economics and Philosophy, 32, 51-73.

Begon, J. (2017). Capabilities for all? From capabilities to function, to capabilities to control. Social Theory and Practice, 43, 154-179.

Begon, J. (2018a). Disability, rationality, and justice: Disambiguating adaptive preferences. In D. Wasserman \& A. Cureton (Eds.), The Oxford handbook of philosophy and disability. Oxford: Oxford University Press.

Begon, J. (2018b). Book review: Elizabeth Barnes, the minority body: A Theory of disability. Journal of Moral Philosophy, 15, 100-103.

Begon, J. (unpublished). Neutral impairment, disadvantageous disability.

Bettcher, T. M. (2014a). Feminist perspectives on trans issues. In E. Zalta (Ed.), The stanford encyclopaedia of philosophy. Retrieved May 16, 2020 from https://plato.stanford.edu/archives/ spr2014/entries/feminism-trans/.

Bettcher, T. M. (2014b). Trapped in the wrong theory: Rethinking trans oppression and resistance. Signs, 39, 383-406. 
Buchanan, A., Brock, D. W., Daniels, N., \& Wikler, D. (2000). From chance to choice: Genetics and justice. Cambridge: Cambridge University Press.

Campbell, S. M., \& Stramondo, J. A. (2016). Review: The minority body by Elizabeth Barnes. Notre Dame Philosophical Reviews. Retrieved May 16, 2020 from https://ndpr.nd.edu/news/the-minoritybody-a-theory-of-disability/.

Campbell, S. M., \& Stramondo, J. A. (2017). The complicated relationship of disability and well-being. Kennedy Institute of Ethics Journal, 27, 151-184.

Carter, I. (2014). Is the capability approach paternalist? Economics and Philosophy, 30, 75-98.

Cohen, G. A. (2011). On the currency of egalitarian justice. In M. Otsuka (Ed.), On the currency of egalitarian justice and other essays in political philosophy (pp. 3-43). Princeton: Princeton University Press.

Crisp, R. (2006). Reasons and the good. Oxford: Oxford University Press.

Daniels, N. (1985). Just health care. Cambridge: Cambridge University Press.

Daniels, N., Rose, S., \& Daniels Zide, E. (2009). Disability, adaptation, and inclusion. In K. Brownlee \& A. Cureton (Eds.), Disability and disadvantage (pp. 54-85). Oxford: Oxford University Press.

Dembroff, R. (forthcoming). Real talk on the metaphysics of gender. Philosophical Topics.

Dougherty, T. (2014). Ethics discussion at PEA Soup: Elizabeth Barnes' "Valuing Disability, Causing Disability". PEA Soup. Available at: https://peasoup.typepad.com/peasoup/2014/11/ethicsdiscussion-at-pea-soup-elizabeth-barnes-valuing-disability-causing-disability-with-critical-p.html.

Dworkin, R. (2000). Sovereign virtue. Cambridge, MA: Harvard University Press.

Elster, J. (1987). Sour grapes: Studies in the subversion of rationality. Cambridge: Cambridge University Press.

Francis, L. (2018). Understanding disability civil rights non-categorically: The minority body and the Americans with disabilities act. Philosophical Studies, 175, 1135-1149.

Gay, R. (2017). Hunger: A memoir of (my) body. London: Corsair.

Gheaus, A. (2013). The feasibility constraint on the concept of justice. The Philosophical Quarterly, 63, 445-464.

Griffin, J. (1986). Well-being: Its meaning, measurement, and moral importance. Oxford: Oxford University Press.

Haslanger, S. (2000). Gender and race: (What) Are they? (what) do we want them to be? Nous, 34, 31-55.

Hawkins, J. (2018). Book review: Elizabeth Barnes, the minority body: A theory of disability. Ethics, $128,462-467$.

Howard, D., \& Aas, S. (2018). On valuing impairment. Philosophical Studies, 175, 1113-1133.

Jenkins, K. (2016). Amelioration and inclusion: Gender identity and the concept of woman. Ethics, 126, 394-421.

Kahane, G., \& Savulescu, J. (2009). The welfarist account of disability. In K. Brownlee \& A. Cureton (Eds.), Disability and disadvantage (pp. 14-53). Oxford: Oxford University Press.

Kahane, G., \& Savulescu, J. (2016). Disability and mere difference. Ethics, 126, 774-788.

Kahneman, D., Slovic, P., \& Tversky, A. (Eds.). (1982). Judgement under uncertainty: Heuristics and biases. Cambridge: Cambridge University Press.

Khader, S. (2011). Adaptive preferences and women's empowerment. Oxford: Oxford University Press.

Kittay, E. F. (2011). Forever small: The strange case of ashley X. Hypatia, 26, 610-631.

McBryde Johnson, H. (2003). Unspeakable conversations. The New York times magazine. http://www. nytimes.com/2003/02/16/magazine/unspeakable-conversations.html. Retrieved from 24 June 2019.

Müller, S. (2009). Body integrity identity disorder (BIID) - Is the amputation of healthy limbs ethically justified? The American Journal of Bioethics, 9, 36-43.

Nussbaum, M. C. (2000). Women and human development. Cambridge: Cambridge University Press.

Nussbaum, M. C. (2006). Frontiers of justice. Cambridge, MA: Harvard University Press.

Oliver, M. (1996). Understanding disability: From theory to practice. Basingstoke: Palgrave.

Parfit, D. (1984). Reasons and persons. Oxford: Oxford University Press.

Rawls, J. (1999). A theory of justice. Cambridge, MA: Harvard University Press.

Savulescu, J., \& Kahane, G. (2009). The moral obligation to create children with the best chance of the best life. Bioethics, 23, 274-290.

Scanlon, T. M. (1975). Preference and urgency. The Journal of Philosophy, 72, 655-669.

Scanlon, T. M. (1998). What we owe to each other. Harvard: Belknap Press.

Sen, A. (1999). Development as freedom. Oxford: Oxford University Press.

Sen, A. (2009). The idea of justice. London: Penguin.

Shakespeare, T. (2006). Disability rights and wrongs: Revisited. New York: Routledge. 
Silvers, A. (2009). No talent? Beyond the worst off! a diverse theory of justice for disability. In K. Brownlee \& A. Cureton (Eds.), Disability and disadvantage (pp. 163-199). Oxford: Oxford University Press.

Smith, S. R. (2001). The social construction of talent: A defence of justice as reciprocity. Journal of Political Philosophy, 9, 19-37.

Sumner, W. (1996). Welfare, happiness, and ethics. Oxford: Oxford University Press.

Terzi, L. (2004). 'The social model of disability: A philosophical critique. Journal of Applied Philosophy, 2, 141-157.

Terzi, L. (2008). Justice and equality in education: A capability perspective on disability and special educational needs. London: Continuum.

Terzi, L. (2009). Vagaries of the natural lottery? Human diversity, disability, and justice: A capability perspective. In K. Brownlee \& A. Cureton (Eds.), Disability and disadvantage (pp. 86-111). Oxford: Oxford University Press.

Wahlert, L., \& Gill, S. (2017). Pathological, disabled, transgender: The ethics, history, laws, and contradictions in models that best serve transgender rights. Kennedy Institute of Ethics Journal, 27, 249-266.

Wasserman, D. (2018). Book review: The minority body: A theory of disability, Elizabeth Barnes. The Philosophical Review, 127, 251-256.

WHO. (2017). Health topics: Disability. Geneva: World Health Organisation. Retrieved from 24 June 2019.

Wolff, J. (2009a). Disability among equals. In K. Brownlee \& A. Cureton (Eds.), Disability and disadvantage (pp. 112-137). Oxford: Oxford University Press.

Wolff, J. (2009b). Disability, status enhancement, personal enhancement, and resource allocation. Economics and Philosophy, 25, 49-68.

Wolff, J., \& de-Shalit, A. (2007). Disadvantage. Oxford: Oxford University Press.

Publisher's Note Springer Nature remains neutral with regard to jurisdictional claims in published maps and institutional affiliations. 